\title{
In-vivo analysis of the permanent incorporation of fluorine in tooth enamel
}

\author{
Guy Demortier* \\ SPS and LARN - Université de Namur 61, rue de Bruxelles B- 5000 Namur, Belgium
}

\begin{abstract}
The enrichment of enamel by fluoride is the most used treatment to reduce the solubility of hydroxyapatite by acid attack. The position of $\mathrm{OH}^{-}$group in the structure of hydroxyapatite, can be partially or fully occupied by fluorine. In this way crystals of fluorohydroxyapatite and fluorapatite are formed. The understanding of this substitution process was a subject of research at LARN (Laboratoire d'Analyse par Réactions Nucléaires) of the University of Namur since more than 40 years. In addition to analytical studies of fluorine in extracted teeth using the emission of gamma-rays induced by protons (2-3 MeV) the method has been applied to the study of the evolution of the fluorine content of incisors and canines directly in the mouth of scientists belonging to our laboratory and to several dentistry faculties and practitioners. Careful tests were undertaken to avoid any radiation damage during in-vivo experiments. Long term retention of fluorine in enamel induced by low energy density laser irradiation after topical application of fluoride gel was observed.
\end{abstract}

\section{Introduction}

Tooth enamel is the most mineralized tissue of the human body. Its composition is about $96 \%$ inorganic and about $4 \mathrm{wt} \%$ of organic material and water. In dentin, the part of inorganic material is less but it represents at least $70 \mathrm{wt} \%$. Dentin contains more $\mathrm{Mg}$ and $\mathrm{Na}$. The inorganic material is mainly composed (92 to $94 \%$ ) by a calcium phosphate related to the hexagonal hydroxyapatite $\left[\mathrm{Ca}_{10}\left(\mathrm{PO}_{4}\right)_{6}(\mathrm{OH})_{2}\right]$, carbonate $(2 \%)$ but also trace elements: fluoride $(0.01-0.05 \%)$, sodium ( 0.24 to $0.66 \%)$, magnesium ( 0.16 to $0.25 \%)$, chloride ( 0.1 to $0.4 \%)$ $[1,2]$. Incorporation of trace elements (including fluorine) in both dentin and enamel is very limited [3]. As fluorine forms insoluble salts with many elements, the substitution of $\mathrm{OH}$ by $\mathrm{F}$ reduces the solubility of apatite by acid attack. Fluorine is of crucial significance for the teeth. It inhibits bacterial growth and modulates metabolism in enamel. It is therefore used in prophylactic teeth supplements [4].

As the fluoride contained in the daily used toothpaste is directly in contact with enamel surfaces what is the physical mechanism which allows the migration of fluorine in the solid phase of apatite due to the extremely slower diffusion process by comparison with the dissolution of gel or paste in the humid atmosphere of the mouth?

The small organic part of the enamel plays an important role in the fixation of $\mathrm{F}$ into the large inorganic content of hydroxyapatite crystals as explained by S. Higham and her collaborators of the School of Dentistry of the University of Liverpool who say [5]:

"The organic part, particularly enamel-specific proteins called enamelins, have a high affinity for binding hydroxyapatite crystals. The inorganic, organic, and water components of enamel are highly organized: millions of carbonated hydroxyapatite crystals are arranged in long, thin structures called rods that are $4 \mu \mathrm{m}$ to $8 \mu \mathrm{m}$ in diameter. It is estimated that the number of rods in a tooth ranges from 5 million in the lower lateral incisor to 12 million in the upper first molar. In general, rods extend at right angles from the dento-enamel junction (the junction between enamel and the layer below it called dentin) to the tooth surface.
Surrounding each rod is a rod sheath made up of a protein matrix of enamelins. The area in between rods is called interrod enamel, or interrod cement. While it has the same crystal".

In other words, fluoride 'catalyzes' the diffusion of calcium and phosphate into the tooth surface, which in turn remineralizes the crystalline structures.

\section{The importance of non-destructive analysis}

The evaluation of the F content in dental enamel is usually done by etching extracted teeth with perchloric acid. This etching gives rise to a total destruction of a 5 to 50 microns thick enamel layer [6]. Furthermore this procedure does not allow the study of the evolution of the $\mathrm{F}$ concentration after treatments with various fluoridated products. The study of this evolution requires the use of a non-destructive technique of quantitative $\mathrm{F}$ analysis which can be repeated on the same region of the tooth enamel. This goal was achieved by proton induced gamma ray emission (PIGE) probably for the first time in 1974 [7]. New developments were initiated and amplified at LARN over the last 40 years on a large variety of extracted teeth (deciduous and permanent) [8-9] and later for the investigation in-vivo [10-17]. The proton beam is produced by a low energy accelerator: a single ended Van de Graff accelerator and later (1998) a Tandem linear accelerator (Figure 1). The proton beam is extracted from the evacuated vessel of the accelerator trough a tin foil of metal supporting the atmospheric pressure.

An extensive bibliography of the available methods for Fluorine analysis in tooth enamel was recently published [18] but the present

*Correspondence to: Guy Demortier, SPS and LARN - Université de Namur 61, rue de Bruxelles B- 5000 Namur, Belgium, E-mail: guy.demortier@unamur.be

Key words: tooth enamel, fluorine, analysis, in-vivo, laser enhanced retention

Received: December 23, 2020; Accepted: January 13, 2021; Published: January 15,2021 


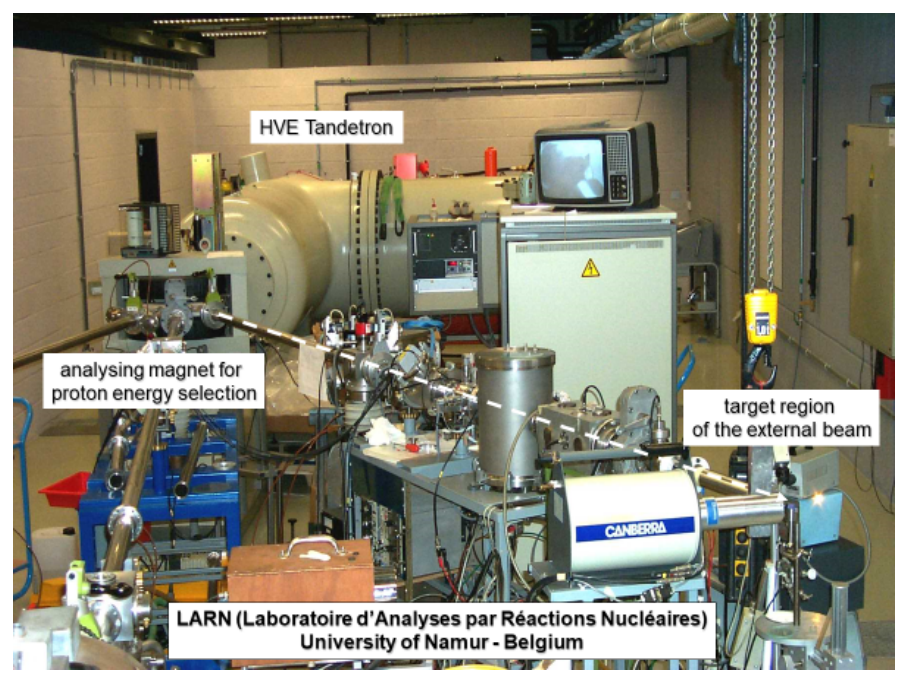

Figure 1. General view of the particle accelerator of LARN. On the right side, the region of external beam analysis (proton beam in vacuum represented with a dashed white line)

summary will concentrate on fluorine migration in the enamel by in-vivo investigations (with a nuclear but non-destructive method of analysis) of about 100 teeth over a period upon 18 months .

\section{Experimental procedure developped at LARN}

\section{Enamel samples}

Extracted teeth (few hundreds) have been collected in several schools of dentistry of the University of Louvain (Dr. J. Vreven) and of the University of Liège (Dr. S. Nammour) to be studied in various conditions of topical fluoridation. It appeared very soon that the content of fluorine in tooth enamel may vary by a factor of 2 even when the probe is moved by less than $2 \mathrm{~mm}$. Measurements on one single specimen (freshly extracted, treated with fluoride gel, stored for days or weeks in various media like pure water, synthetic saliva, or simply in air) were repeated on the same region of the tooth enamel with an incident proton beam spot of $0.7 \mathrm{~mm}$ in diameter. The experimental arrangement (with the tooth enamel sample embedded in a methylmetacrylate resin) for PIGE analyses is presented in Figures 2 and 3.

The original concentration of fluorine in freshly extracted teeth was observed to be higher for young people than for older. This original concentration of fluorine is widely spread: from 100 to $5000 \mathrm{ppm}$ in a batch of 120 specimens. Results of the successive fluoridation treatments on extracted teeth are discussed below.

For in-vivo study, several mouthguards were fabricated for each "patient" (who does not suffer at all!): one specimen for each tooth to be investigated (incisors and canines only due to the impossible accessibility of molars for the proton beam). Specimens for upper and lower jaws are given in Figure 4. More than 60 people were involved in various campaigns of in-vivo analyses. They belong to dental clinics and to LARN (including the author of this report).

Mouthpieces are made with methylmetacrylate resin. This resin is completely F- free. A brass cylinder is embedded in the resin at the required position for the irradiation of each tooth. This brass cylinder fits exactly to the cylindrical extremity of the proton beam tube (Figure 5 ). With this equipment, it is possible to repeat the measurements at the same place of each tooth at different periods. No heating sensation is felt by the "patient" during the bombardment. As patient for several runs during more than 30 years the author certifies that the experiment is fully safe.

\section{Choice of the incident proton energy}

Having in mind the application of the technology for in-vivo measurements, the whole irradiation facility is to be installed outside the evacuated accelerator vessel: non-vacuum PIGE. The energy of the incident protons is to be limited to avoid the production of neutrons. The selected proton energy and its intensity are to be sufficient to achieve an acceptable counting rate in the gamma-ray detector (to limit the statistical errors) considering also the limited duration of the beam irradiation of the tooth of the people "taped" at the end of the proton beam pipe.

The final options were: proton energy $2.7 \mathrm{MeV}$, beam intensity $30 \mathrm{nA}$, duration of irradiation 30 seconds. With these experimental conditions, the power dissipated in the tooth enamel is 0.055 watt. The protons cross the enamel along a straight line and are stopped at 30 to 40 microns below the enamel surface. As the number of emitted

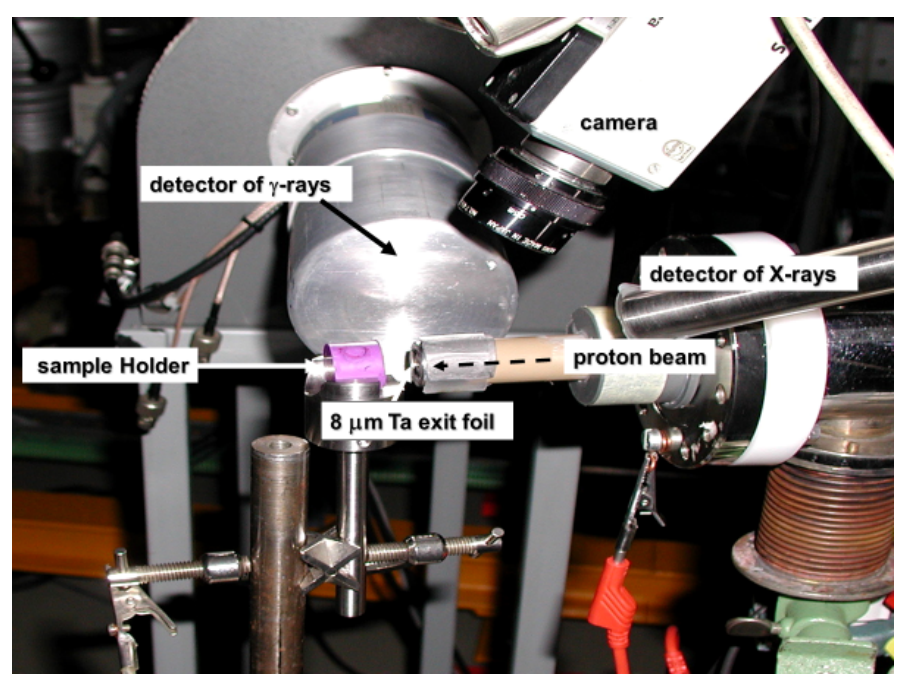

Figure 2. The experimental beam line used for the PIGE study of extracted teeth. The $\mathrm{X}$-ray detector is only used to quantify the content of calcium and elements which cannot be detected by their gamma-ray characteristic lines

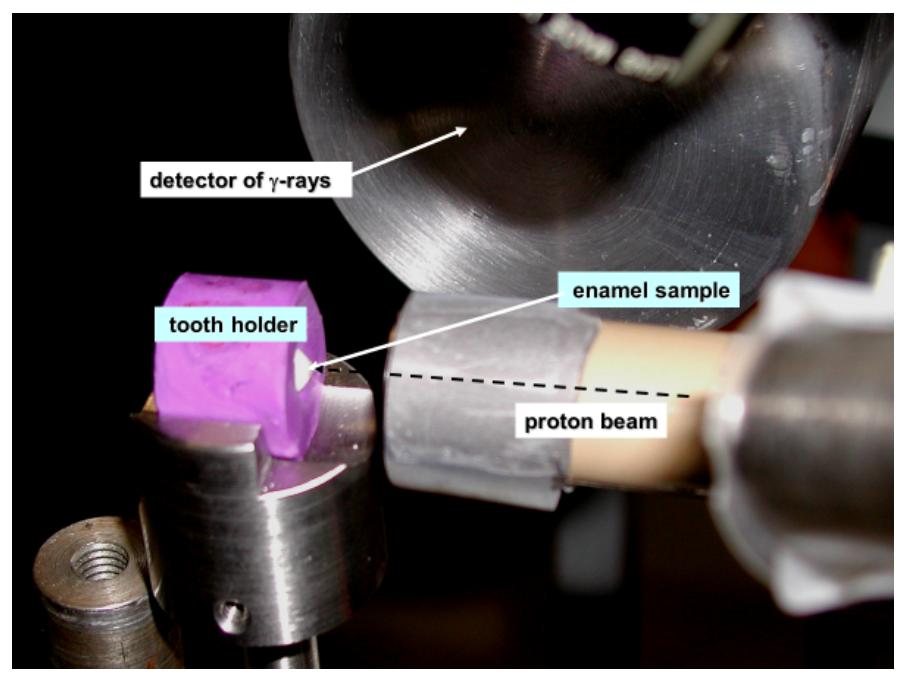

Figure 3. Closer view of proton irradiation region of extracted tooth 


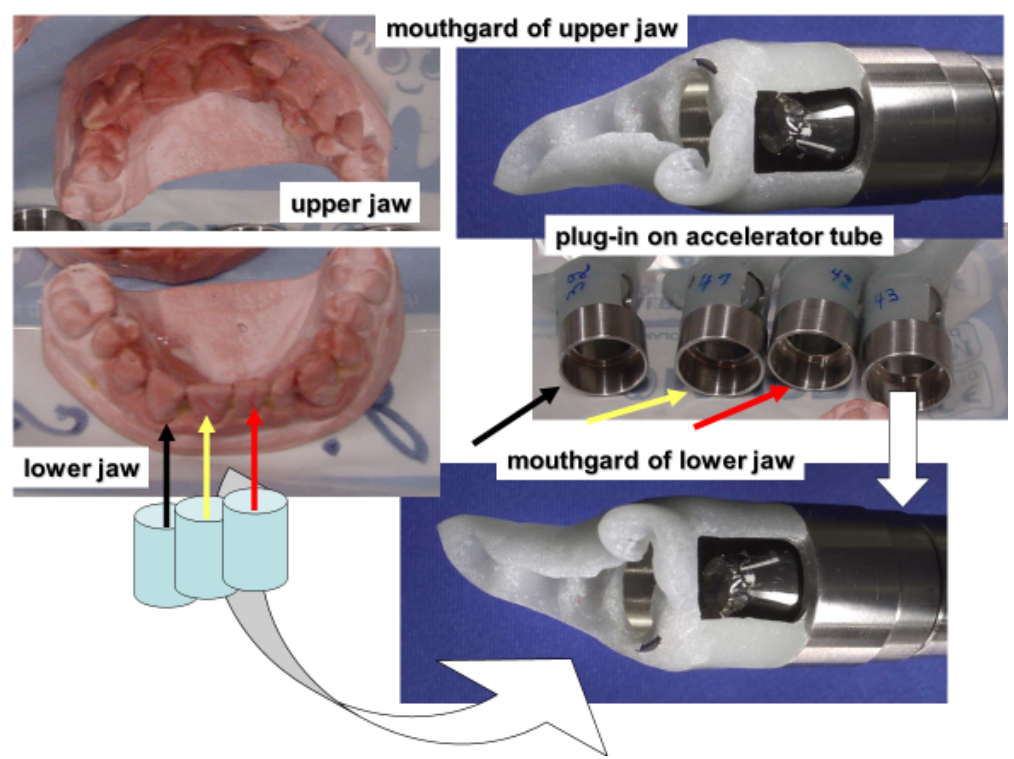

Figure 4. Mouthgards for the individual irradiation of teeth and their plug-in on accelerator tube

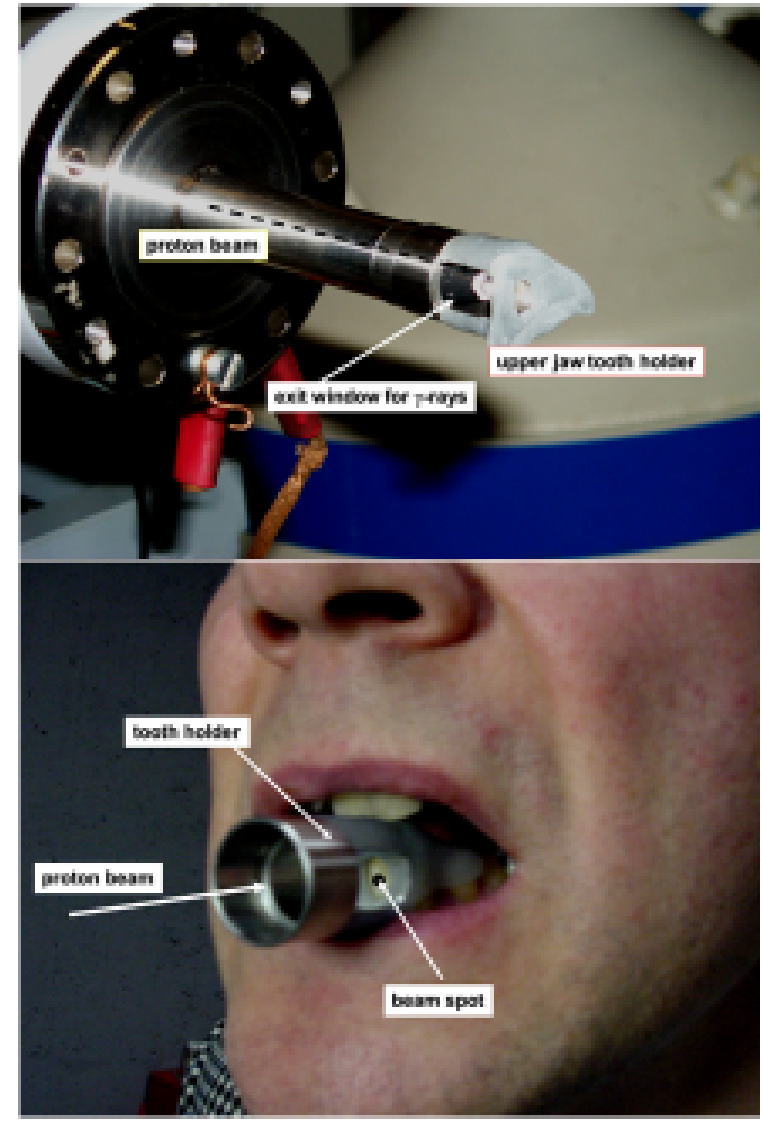

Figure 5. Part a: the mouthgard of upper jaw plugged on the accelerator tube for in-vivo analysis. Part b: the plug-in system on a lower jaw for in-vivo analysis 
gamma-rays sharply decreases with the decreasing of proton energy the thickness of the analysed enamel does not exceed 20 microns.

For lower energies of incident protons it would then have been necessary to increase the duration of the irradiation, which would have been uncomfortable for people "taped" at the end of the proton beam pipe.

The working proton energy is below the threshold for neutron production by all the elements usually present in the enamel: $\mathrm{Ca}, \mathrm{P}, \mathrm{O}$, with very low amount of $\mathrm{F}, \mathrm{Na}, \mathrm{Mg}, \mathrm{Cl}$.

$\mathrm{O}^{16}$ and $\mathrm{Ca}^{40}$ are very stable nuclei: consequently the excitation of their first energy level (6.502 and $3.348 \mathrm{MeV}$ respectively) cannot be reached by inelastic proton scattering $(2.7 \mathrm{MeV})$. They do not give rise to any significant gamma-ray emission. Bombardment of a $\mathrm{CaO}$ target in the same experimental conditions has proven that no significant gamma-ray signal of the other lower rich isotopes of $\mathrm{Ca}$ and $\mathrm{O}$ was present.

Characteristic gamma-ray lines produced by proton bombardment with energies between 1 and $4 \mathrm{MeV}$ on many elements were studied in previous works [18].The identification of all the gamma-ray lines produced by the bombardment of tooth is given in Figure 6. In addition to the expected elements $\mathrm{O}, \mathrm{F}, \mathrm{Na}, \mathrm{Mg} \mathrm{P}, \mathrm{Cl}$, and $\mathrm{Ca}$, we have added $\mathrm{Li}$ and Ta.

Traces of Li in tooth enamel was never reported but its presence, highly unlikely, could be due to some Li substitute of Na. Low energy proton interaction with $\mathrm{Li}$ is extensively studied by astrophysicists interested by the nucleosynthesis. The threshold proton energy to initiate neutron production under bombardment of $\mathrm{Li}$ is perfectly known. By browsing the list of candidates from the lightest, the nucleus

\begin{tabular}{|c|c|c|c|}
\hline Element & Isotope & $\begin{array}{l}\text { Gamma-ray } \\
\text { energy (keV) }\end{array}$ & Origin \\
\hline $\mathrm{Li}$ & 7 & 477 & $c, e$ \\
\hline c & 12 & 2357 & $p, c$ \\
\hline \multirow[t]{2}{*}{$F$} & 19 & 110 & $c, e$ \\
\hline & & 197 & $c, e$ \\
\hline \multirow[t]{3}{*}{$\mathrm{Na}$} & 23 & 439 & $c, e$ \\
\hline & & 1368 & p.c \\
\hline & & 1630 & $p, \alpha$ \\
\hline \multirow[t]{7}{*}{$\mathrm{Mg}$} & 26 & 170 & $\mathrm{p}, \mathrm{c}$ \\
\hline & 25 & 390 & $c, e$ \\
\hline & 25 & 586 & $c, e$ \\
\hline & 26 & 843 & $\mathrm{p}, \mathrm{c}$ \\
\hline & 25 & 976 & $c, e$ \\
\hline & 26 & 1013 & $p, c$ \\
\hline & 24 & 1368 & $c, e$ \\
\hline \multirow[t]{3}{*}{$P$} & 31 & 1266 & $c, e$ \\
\hline & & 1778 & $\mathrm{p}, \alpha$ \\
\hline & & 2237 & $p, c$ \\
\hline \multirow[t]{4}{*}{$\mathrm{Cl}$} & 35 & 1220 & $c, e$ \\
\hline & 37 & 2127 & $\mathrm{p}, \alpha$ \\
\hline & 37 & 2168 & $\mathrm{p}, \mathrm{c}$ \\
\hline & 35 & 2237 & $\mathrm{p}, \alpha$ \\
\hline Ta & 181 & 136 & $c, e$ \\
\hline
\end{tabular}

Figure 6. Gamma-ray lines produced by $2.7 \mathrm{MeV}$ protons on tooth enamel and on potential surrounding material (c,e : coulomb excitation of isotope; $p, c$ : proton capture $; \mathrm{p}, \square$ : emitted alpha particle under proton bombardment of $\mathrm{Li}^{7}$ is known to be the second candidate (the first one being Tritium!) able to liberate neutrons by protons with energies higher than 1.880 $\mathrm{MeV}$ [19]. Fortunately the presence of $\mathrm{Li}$ in the target region would give a warning signal in the gamma-ray spectrum at $477 \mathrm{keV}$ in order to immediately stop the irradiation. It never happened. Other candidates for $(\mathrm{p}, \mathrm{n})$ reactions are $\mathrm{Be}^{11}$ and $\mathrm{F}^{19}$ but the corresponding threshold proton energies are $3.016 \mathrm{MeV}$ and $4.234 \mathrm{MeV}$ respectively.

The choice of a Ta exit foil offers several advantages. The thickness of the foil is sufficient to maintain the atmospheric pressure and dissipate the heat. It can only undergo a coulomb excitation and produce X-rays and gamma-rays. These signals are used to monitor the total charge deposited by the protons in the irradiated specimen and therefore to quantify the elemental F concentration by comparison with a selected reference material. In the present investigations the reference material is a piece of glass containing $0.1 \%$ of $\mathrm{F}$.

\section{Geometry of the irradiation area}

The lateral size of the proton beam $(3 \mathrm{MeV})$ emerging from the electromagnetic analyser of the accelerator is limited by 2 graphite collimators ( $2 \mathrm{~mm}$ diameter): the distance between them is $40 \mathrm{~cm}$. The accelerator pipe is extended by a narrower pipe which is closed with a tantalum foil $\left(4.15 \mathrm{mg} / \mathrm{cm}^{2}\right)$. Except for the tantalum window the incident protons may only hit pure graphite. As the energy of the first excitation state of $\mathrm{C}^{12}$ is $4.43 \mathrm{MeV}, 2.7 \mathrm{MeV}$ protons cannot induce additional gamma-ray emission. The protons emerging out of this window loose $0.185 \mathrm{MeV}$. They finally cross $0.8 \mathrm{~cm}$ in air (loosing again $115 \mathrm{keV}$ ) before hitting the surface of the tooth. The final proton energy is then $2.7 \mathrm{MeV}$ when reaching the tooth surface.

\section{Non destructive and security aspects}

\section{Potential defects on enamel after irradiation}

The slowing dawn of moderate energy protons (a few $\mathrm{MeV}$ ) is essentially due to ionization but recoil effects of nuclei are not expected. The fact was verified on several extracted teeth which were irradiated in the configuration of Figure 3 for 60 minutes (a duration 120 times higher than in the analysis protocol). The samples (before and after irradiation) were examined under an electron microscope with a magnification of 15000 , revealing no difference: the crystal structure of the enamel stays perfectly intact and each specimen may be studied several times. It is worth to add that no trace of the irradiation was observed on living teeth, even several years after repeated runs of invivo experiments [11].

This low destructivity of tooth enamel under proton bombardment is attributed to the high binding energy of atoms in hydroxyapatite and/ or fluorapatite : ionization is rapidly followed by a recombination of the electron clouds. Nuclear recoil effects are small, since most nuclei of apatite have large atomic mass by comparison with the proton mass. On the contrary samples of dentin (which its higher organic part) would rapidly burn under proton bombardment. This situation never happened due to the large enamel thickness by comparison with the proton range.

\section{Safety check}

Before starting in vivo experiments, safety checks have been made by installing a head phantom (with a tooth enamel sample at the natural location) in the geometrical arrangement already described. Various dosimeters installed at various positions in the phantom were used 
to estimate the X-ray, gamma-ray and neutron absorbed doses in the geometry used for in-vivo measurements. Like for the study of defects the irradiation time was also 1 hour. The results are given in Figure 7. The absorbed dose is several orders of magnitude below that received by a patient for classical tooth radiography $(0.005 \mathrm{mSv})$.

\section{PIGE results}

A typical gamma-ray spectrum collected during the bombardment of a tooth is reproduced in Figure 8. High energy X-rays and gammarays are collected by a high resolution $\mathrm{Ge}(\mathrm{Li})$ detector which is calibrated in energy and efficiency. When protons cross the exit foil of Ta, they produce $\mathrm{K} \mathrm{X}$-ray lines (57 and $64 \mathrm{keV}$ ) but also $136 \mathrm{KeV}$ gamma-rays which are used to monitor the successive measurements. One observes the characteristic gamma-ray lines of $\mathrm{F}$ (110 and $197 \mathrm{kev}), \mathrm{Na}(437 \mathrm{keV})$ and $\mathrm{P}(1230 \mathrm{keV})$ but also low intensity, gamma-rays of $\mathrm{Mg}$. The signal at $511 \mathrm{keV}$ comes from the annihilation of positrons produced be the interaction of protons with any material. During in-vivo analyses, the staff in charge of the collection of the photon spectra keeps under close watch if no gamma-ray line at $477 \mathrm{keV}$ is present: a check certifying the absence of neutron production.

\section{Fluorine retention after various treatments}

\section{The importance of the organic part of the enamel}

A documented discussion of the advantages of topical application of fluoride gels for protect the tooth enamel may be found in previous works [7 to 16]. It is expected that the Fluorine content in the analysed portion of the enamel (maximum 20 microns) gradually decreases with time. The general trend of the F content in the enamel after topical application of a fluoride gel has a limited efficiency: additional $\mathrm{F}$ concentration disappears after about 5 weeks (Figure 9) [7].

The F- decrease concerns only the first 20 microns below the enamel surface (the maximum thickness reached by the PIGE analytical technique) and can be attributed to the elimination in saliva but it is not excluded that it may the consequence of F migration deeper in the rods through the organic component of the enamel. The two mechanisms probably act simultaneously. It is useful to remind: "The organic part, particularly enamel-specific proteins called enamelins, have a high affinity for binding hydroxyapatite crystals." [4]. Enamelin is indeed the

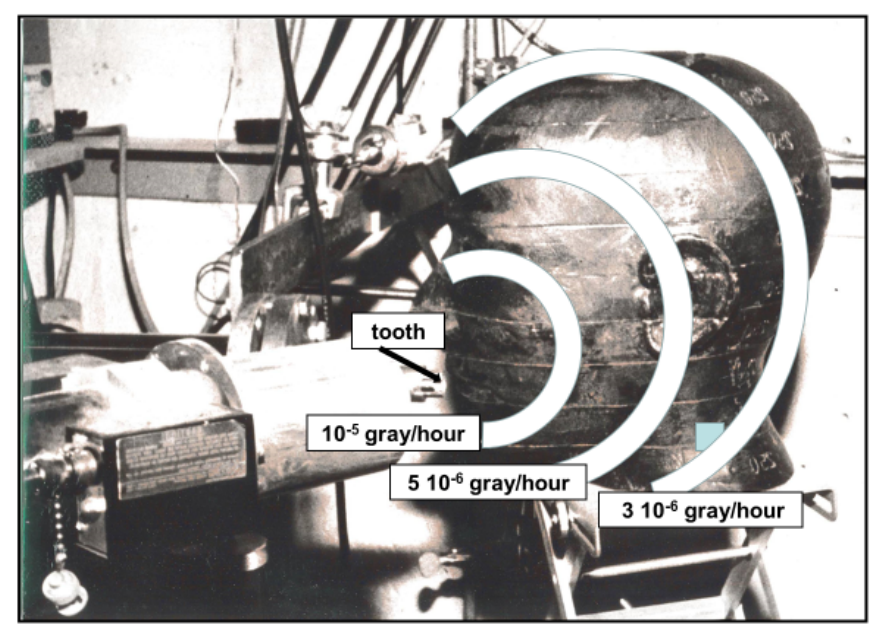

Figure 7. Security check phantom (used before in vivo analysis)
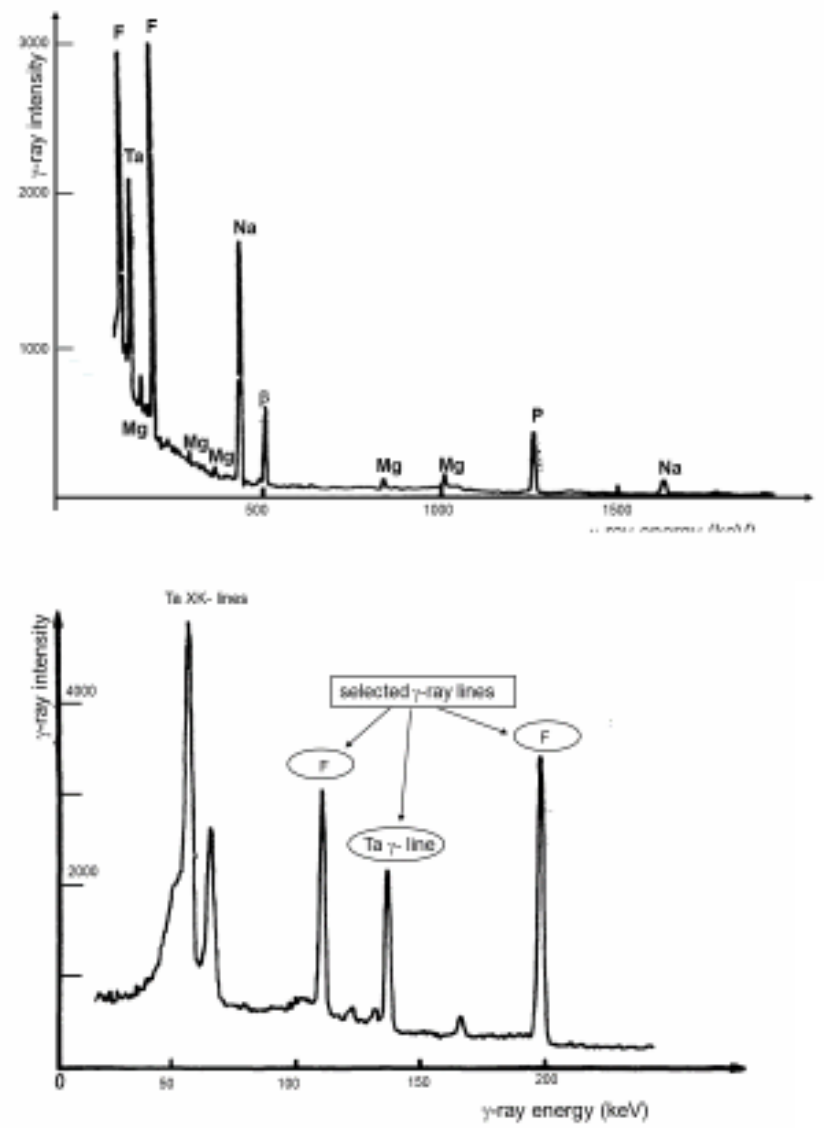

Figure 8. Part a : Full scale gamma-ray spectrum produced by the bombardment of a tooth with $2.7 \mathrm{MeV}$ proton beam. Part b: Selected gamma-ray lines used for the quantitative analysis of fluorine

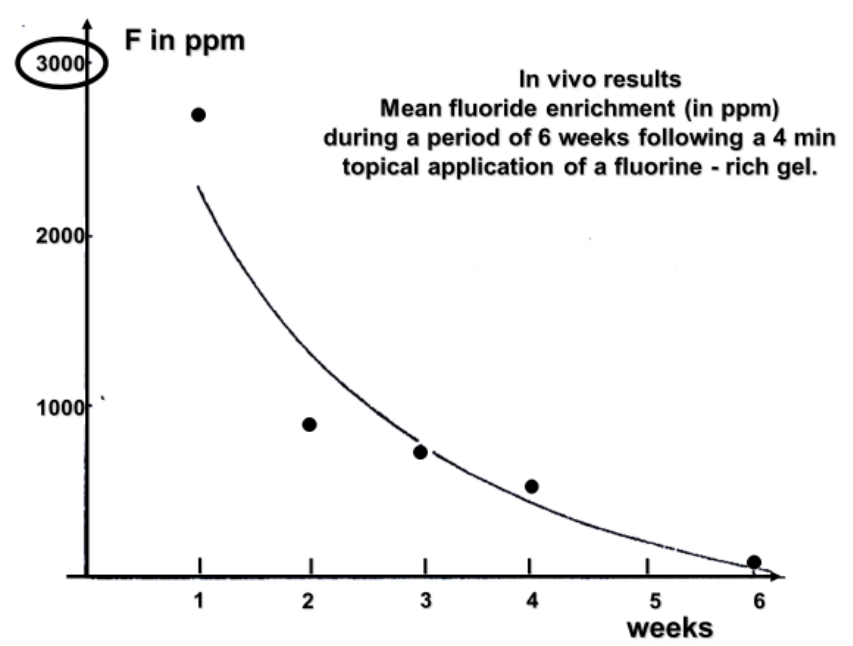

Figure 9. Evolution of fluorine content in a tooth enamel sample irradiated in vivo at the same location once every week

largest protein in the enamel matrix of developing teeth and is present predominantly at the growing enamel surface. The fluoride deposited on the enamel surface resulting from fluoride topical application may be seen as a reservoir releasing fluoride [20]. This reservoir of CaF2 releases fluoride during about 5 days [21]. 


\section{Does laser irradiation improve the fluorine retention?}

As laser practitioner in his dental office, Dr. S. Nammour [14,15] suggested to study the influence of laser interaction with tooth enamel in various steps of fluoridation. A low energy density argon laser (requiring no water cooling) was used with uniform operating conditions: $10 \mathrm{~J} / \mathrm{cm}^{2}$, output power $340 \mathrm{~mW}$, laser irradiation time 30 seconds) on extracted teeth and in vivo PIGE analyses. Investigations started on extracted teeth and then in-vivo.

\section{Laser irradiation of extracted teeth}

Enamel was removed from 120 extracted teeth to obtain 240 samples (front face and rear face) of $3 \mathrm{~mm} \times 3 \mathrm{~mm}$. The "patients" belong to a large variety of age with a great proportion of children teeth. The $\mathrm{F}$ concentration was measured on all samples before any treatment. The $\mathrm{F}$ concentration on the whole collection was measured in the geometrical arrangement of Figure 3. No difference was observed between front and rear faces.

All samples were then treated with acidulated phosphate fluoride (1.23\% fluoride ions; $\mathrm{pH} 3.5$ ) by topical application for $5 \mathrm{~min}$ followed by a $1 \mathrm{~min}$ rinsing in distilled water. The collection was then divided in two equivalent groups $\mathrm{F}$ (for fluoridation only) and FL (for fluoridation followed by laser irradiation). As the initial concentration is known for each of the 240 teeth, the selection was made to get the same distribution of F content in each sub-group. The samples of the FL group were treated with the argon laser in the conditions given above. Both groups were analysed in the 10 minutes following the application of gel (and laser treatment for FL). Immediately after the application of the fluoride gel the $\mathrm{F}$ concentration increases by $64 \pm 8 \%$ for group $\mathrm{F}$ and $60 \pm 8 \%$ for group FL. Laser irradiation following the topical treatment has no influence on the fluorine migration.

Batches were taken from each group: 40 for the "F-air "sub-group and 40 for the "FL-air" sub-group and stored in air, with no turbulence, for 7 days and analysed again by PIGE. A decrease of $50 \%$ of the apparent F concentration (respectively $51 \%$ and $42 \%$ ) was observed for both groups (lased or not) as already observed for earlier observations: no significant influence of the laser treatment for samples collected in air after treatment. The fluorine has one single way to migrate: into the enamel and certainly not in air. During the week between the 2 analyses Fluorine migrate deeper than 20 microns in the enamel and cannot be detected by PIGE.

The other samples ( 80 belonging to each group) called "F-water" and "FL-water" were stored in distilled water for the same period of 7 days and PIGE measurements were performed again. Samples of the "F-water" sub-group have completely lost, in water, the additional $\mathrm{F}$ content brougth by the topical application of gel but $50 \%$ of this added $\mathrm{F}$ content were already preserved in samples of the "FL-water" subgroup. As observed for the "F-air" and "FL-air" sub-groups this apparent decrease of F in the "FL-water" sub-group is not due to F loss in water but, at least partially if not completely, to F migration deeper inside the enamel and consequently outside the region which can be reached by protons to produce the gamma-rays. The apparent conclusion is that the laser treatment closes the organic channels thwarting the F draining in water. Let us repeat the words of the Higham team [4]. "The organic part, particularly enamel-specific proteins called enamelins, have a high affinity for binding hydroxyapatite crystals.

\section{Laser irradiation of living teeth}

Let us finally investigate the influence of laser irradiation on living teeth. Successive runs for in-.vivo studies were organized including the analysis of 98 teeth (incisors and canines) belonging to 12 'patients' of age ranging from 45 to 62 years. Figure 10 shows the installation of a participant for the proton irradiation of a lower canine. The mean value of the initial $\mathrm{F}$ concentrations was a bit lower than $600 \mathrm{ppm}$. In RUN 1, teeth were analysed without any treatment. RUN 2 were then lunched on teeth immediately after topical application of the acidulated phosphate fluoride used in the previous in-vitro campaigns (4 minutes of gel application only and rinsing of the mouth, irradiation with the $11 \mathrm{~J} / \mathrm{cm}^{2}$ laser beam for $30 \mathrm{~s}$ for only one tooth on two in order to appreciate the efficiency of the laser irradiation). RUN 3, RUN 4 and RUN 5 took place after 7 days, 6 months and 18 months respectively. Results of RUN 3 (7days) indicate that the F uptake is 3.5 times better for lased teeth (43\% remaining for lased teeth versus $12 \%$ for other ones). This factor increases to 5 for RUN 4 (15\% relative to $3 \%)$. The uptake is already of $11 \%$ after 18 months (RUN) for lased teeth by comparison with the complete disappearance of any uptake if no laser irradiation was performed.

The final model of fluorine migration in the first 20 microns of the tooth enamel is summarized in Figure 11. The fluorine migration starts in the soft narrow channels of inter-prismatic substance of the tooth enamel (horizontal white arrows) before moving laterally in the

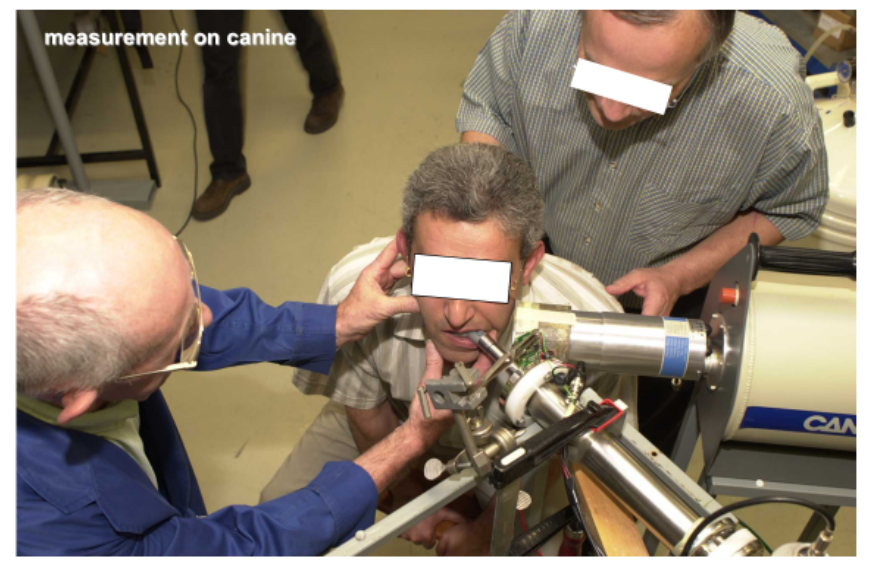

Figure 10. The installation of a 'patient' for in-vivo analysis of a canine

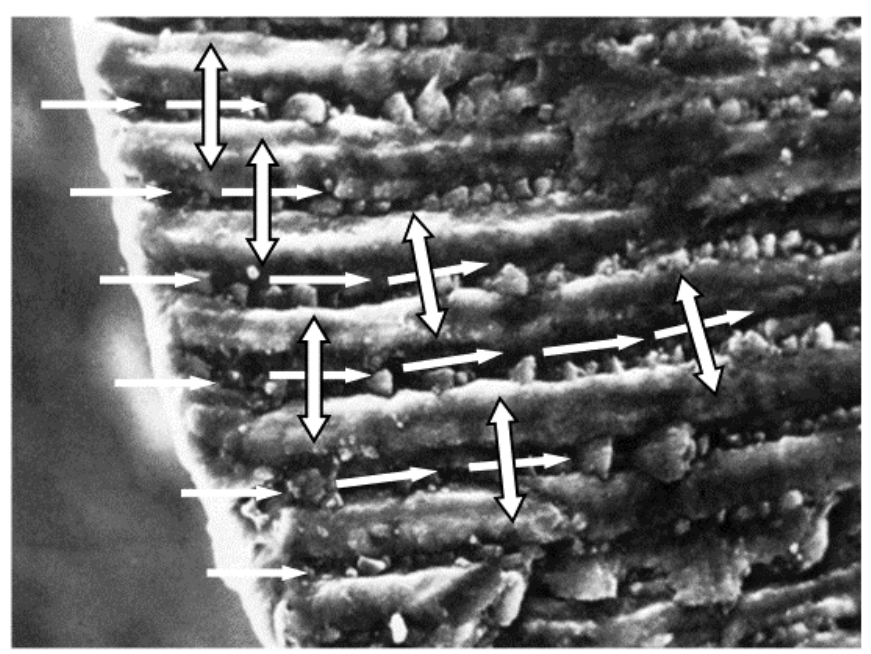

Figure 11. Fluorine migration in tooth enamel: first step (white single way arrows) fast fluorine migration in the organic part and, second step (double way arrows) slow migration from the organic part into the hard inorganic crystalline phase 
hard prisms (double vertical arrows) as illustrated in Figure 11. Laser irradiation of the tooth inhibits the evacuation, in the saliva, of fluorine from the soft inter-prismatic substance to increase the time of migration in the highly crystallised prisms.

\section{Conclusions}

PIGE has proven to be outstanding for the non-destructive analysis of $\mathrm{F}$ content in tooth enamel down to 20 microns below the surface. Protons with energy of a few $\mathrm{MeV}$ do not induce any destruction of the tooth enamel and repeated measurements at the same location on enamel after fluoride treatments allow following the F migration. The technology, while using a nuclear particle accelerator, is completely safe to allow in-vivo analyses. Even if the tooth enamel is a highly mineralized solid, the importance of the small amount of organic material has been recognized for binding hydroxyapatite crystals: this organic component is the driving 'soft' medium able to transport the $\mathrm{F}$ anions between the apatite rods of the enamel before their substitution with $\mathrm{OH}$ anions into the apatite. Fluorine introduced on the tooth enamel by topical application of fluoride gels is indeed rapidly evacuated in water (and saliva) as shown in the studies of extracted teeth. Laser irradiation of tooth in addition to application of fluoride gel increases the permanent incorporation of $\mathrm{F}$ in the enamel.

\section{Acknowledgments}

Pioneer investigation, in 1974, of migration of fluorine in tooth enamel was the subject of the $\mathrm{PhD}$ thesis of Josiane Stroobants-Baijot supervised by Professor Gaston Deconninck, with active contributions of Franz Bodart and Yvon Morciaux. To them all I testify my greatest gratitude. Improvements in that field were suggested to me by Professor Samir Nammour at the end of the $80^{\text {th }}$ to check the role of laser irradiation to improve the retention of the fluorine content in tooth enamel. Acknowledgments are addressed to chemists and physicists of LARN and dentists belonging to the team of Samir Nammour for their fruitful discussions and their participation in numerous runs of in vivo analyses.

\section{Conflicts of interest}

The author declares no conflicts of interest in this paper.

\section{References}

1. Gutierez-Salazar M, Reyes-Gasg J (2003) Microhardness and chemical composition of human tooth. Material Research (on line) 6(3): 367-373.

2. Weatherell JA (1975) Composition of dental enamel. British Medical Bulletin 31(2): 115-119.

3. Hong H, Tie I, Jian T (2006) The crystal characteristics of enamel and dentin by XRD method. Journal of Wuhan University of Technology - Material Science 21(1): 9.
4. Siverstone LM (1977) Remineralisation phenomena. Caries Research 11(Supplement 1): $59-84$.

5. Higham S, Hope C.H, Valappil S, Smith Ph, Enamel structure and composition. Caries Process and prevention strategies: The Host, (free access course) //www.dentalcare. com/en-us/professional-education/ce-courses/ce370

6. Arenos J, Schuthof J (1975) Perchloric acid etching of tooth enamel. Caries Research 9: 363-37.

7. Rytomaa I, Keikonen J, Anttila A (1974) Sensitive physical method for determination of fluorine distribution in human surface enamel. Archives of Oral Biology 19(7): 553556. [Crossref]

8. Baijot-Stroobants J (1976) Etude par réactions nucléaires de la migration du fluor dans l'émail dentaire humain après application topique in vivo. Ph.D. Thesis, University of Namur (Belgium).

9. Baijot-Stroobants J, Vreven J (1979) Determination by charged particles activation of fluorine uptake in human dental enamel. Caries Research 13(4): 211-217. [Crossref]

10. Stroobants J, Bodart F, Deconninck G, Demortier G, Nicolas G (1976) Analysis of fluorine by nuclear reactions and application to human dental enamel. Ion Beam Surface Layer Analysis 2: 933-943.

11. Baijot-Stroobants J, Vreven J (1980) In-vivo uptake of topically applied fluoride by human dental enamel. Archives of Oral Biology 25(8-9): 617-621. [Crossref]

12. Baijot-Stroobants J, Bodart F, Deconninck G, Vreven J (1979) Radiation exposure during in vivo analysis of human dental enamel by proton irradiation. Health Physics 36(3): 423-428. [Crossref]

13. Baijot-Stroobants J, Bodart F, Deconninck G, Vreven J (1981) Large scale study of tooth enamel. IEEE Transactions on Nuclear Science 28(2): 1401-1403.

14. Demortier G (1995) Analysis of light elements with a nuclear microprobe -A review. Nuclear Instruments and Methods in Physics Research B 104(1-4): 244-254.

15. Nammour S, Demortier G, Florio P, Delhaye Y, Pireaux J-J, Morciaux Y, Powell L (2003) Increase of enamel fluoride retention by low fluence argon laser in vivo. Lasers in Surgery and Medicine 33(4): 260-263.

16. Nammour S, Rocca J-P, Pireaux J-J, Powell L, Morciaux Y, Demortier G (2005) Increase of enamel fluoride retention by low fluence argon laser beam: a 6-month follow-up study in vivo. Lasers in Surgery and Medicine 36(3): 220-224.

17. Demortier G, Nammour S (2008) In-vivo PIXE-PIGE study of enhanced retention of fluorine in tooth enamel after laser irradiation. Nuclear Instruments and Methods in Physics Research B 266(10): 2408-2411.

18. Preoteasa EA, Preoteasa ES, Suciu I, Bartok RN (2018) Atomic and nuclear analysis methods for dental materials: A Review. AIMS Material Sciences 5(4): 781-844.

19. Deconninck G, Demortier G (1973) Dosage d'échantillons métalliques par réactions nucléaires et atomiques promptes. IAEA-SM 159/27: 573-589.

20. Johnson CH, Trail CC, Galonsky A (1964) Threshods for (p,n) reactions on 26 intermediate weight nuclei. Physical Review 136B(6): 1719.

21. Wefel JS, Harless JD (1981) The effect of topical fluoride agents on fluoride uptake and surface morphology. Dental Research 60(11): 1842-1848. [Crossref]

22. Attin T, Hartman O, Hilgers R.D, Hellwig E (1995) Fluoride retention of incipient enamel lesions after treatment with calcium fluoride varnish in vivo. Archives Oral Biology 40(3): 169-174. [Crossref]

Copyright: (2021 Demortier G. This is an open-access article distributed under the terms of the Creative Commons Attribution License, which permits unrestricted use, distribution, and reproduction in any medium, provided the original author and source are credited. 